Aljinatın nem ÖZET

dengesinin

korunmasında yeni bir

yöntem

\section{A new method in protection of moisture balance of alginate}

\author{
Dr. Öğr. Üyesi Gözde Memişoğlu \\ Medipol Üniversitesi, Diş Hekimliği Fakültesi, \\ Protetik Diş Tedavisi AD., İstanbul \\ Orcid ID: 0000-0001-5800-5080
}

\section{Dr. Öğr. Üyesi Çağlar Bilmenoğlu}

Trakya Üniversitesi, Diş Hekimliği Fakültesi,

Protetik Diş Tedavisi AD., Edirne

Orcid ID: 0000-0002-2580-9899

\section{Geliş tarihi: 17 Mart 2020}

Kabul tarihi: 25 Eylül 2020

doi: 10.5505/yeditepe.2021.45722

\author{
Yazışma adresi: \\ Dr. Öğr. Üyesi Çağlar Bilmenoğlu \\ Trakya Üniversitesi, Diş Hekimliği Fakültesi, \\ Protetik Diş Tedavisi AD., Edirne \\ 22130 İskender/Edirne Merkez/Edirne \\ Tel: 905556210131 \\ E-posta: dtcaglarbilmenoglu@gmail.com
}

Amaç: Bu çalışmanın amacı hidrofobik ortamda bekletilen aljinatın farklı zaman aralıklarında boyutsal değişimini değerlendirmektir.

Gereç ve Yöntem: Fabrikasyon olarak üretilmiş dişsiz bir üst çene modeli master model olarak seçilmiş, üzerine ölçü malzemesine standart kalınlık sağlanabilecek şekilde mum yerleştirilip, delikli akrilik kaşık üretilmiştir. Her grup için 10'ar kez aljinat ile ölçü alınmıştır. Alınan aljinat ölçüler 4 farklı ortam (kuru ortamda, su içerisinde, yağ içerisinde ve nemlendirilmiş bir kağıt havlu ile birlikte vakumlu bir poşet içerisinde) içerisinde 72 saat bekletilmiştir. Her grup için 10, toplamda 40 ölçü alınmıştır. 0., 1., 3., 6., 12., 24., 48. ve 72. saatlerde ağız dışı tarayıcı ile ölçüler dijitalize edilmiş ve yine dijitalize edilen master model ile yüzey çakıştırması yapılmıştır. Ölçümler 3'er kez tekrarlanmış ve master modelden sapma değerlerinin ortalaması alınmıştır. Klinik şartları taklit etmek için ölçü $2 \mathrm{~kg}$ basınç altında 3dk bekletilmiş daha sonra da su altında yıkanmıştır.

Bulgular: Shapiro-Wilk testi sonucu verilerin normal dağıldığı belirlenmiştir. Gruplar arası farkın anlamlı olup olmadığı Ancova ile değerlendirilmiştir. Bütün saat aralıklarında nemli ortamda ve yağ içerisinde bekletilen aljinatlar arasında anlamlı bir fark bulunmazken, su ve kuru ortamda bekletilen aljinatların nemli ortamda bekletilenlere göre anlamlı derecede boyutsal değişim gösterdiği görülmüştür. $(p>0,05)$. 72 . saat sonunda yağ, nem, su ve kuru ortamda bekletilen aljinatların değişim miktarları oransal olarak sırasıyla 2.521; 2.096; $10.553 ; 27.776$ olarak belirlenmiştir.

Sonuç: Aljinatın boyutsal değişimi hem zamana hem de saklandığı koşula bağlıdır. Aljinatın yağ içerisinde bekletilmesi döküm öncesi süresinin arttırımasında yeni bir yöntem olarak göz önünde bulundurabilir.

Anahtar kelimeler: aljinat, nem dengesi, boyutsal stabilite, irreversibl hidrokolloid, dental ölçü

\section{SUMMARY}

Introduction: The aim of this study is to evaluate the dimensional change of alginate, which is kept in hydrophobic environment, at different time intervals.

Methods: A fabricated edentulous maxillary model is choosen as a master model and an acrylic tray is produced. Impressions are made with alginate 10 times for each group. The impressions kept in 4 different environments (in dry environment, in water, oil and in a vacuum bag with a moistened paper towel) for 72 hours. At the 0,1,3,6,12,24,48 and 72hours, the impressions are digitized and superimposition is made with the digitized master model. Measurements are repeated 3 times and the deviation values from the master model are averaged. To imitate clinical conditions, the impressions are kept under $2 \mathrm{~kg}$ pressure for 3 minutes and then washed under water.

Results: As a result of Shapiro-Wilk test, it was determined that the data were normally distributed. Whether the difference between groups is significant was evaluated with Ancova. 
While there was no significant difference between the alginates kept in moist and oil at all hour intervals. Dimensional change amounts of alginates (oil, moisture, water and dry) kept in 4 different environments at the end of the 72nd hour were determined as 2.521; 2.096; 10.553; 27.776 respectively.

Conclusions: The dimensional change of alginate depends on both the time and the condition it is stored. Storing the alginate in oil can be considered as a new method to increase the pre-casting time.

Keywords: Alginate, moisture balance, dimention stability, irreversible hydrocolloid, dental impression

\section{Giriș}

Geri dönüşümsüz hidrokolloid olarak da bilinen aljinat en sık kullanılan diş hekimliği ölçü malzemelerindendir. Uygulama kolaylığı, ekonomik olması, hastayı rahatsız etmemesi aljinatı model elde edilmesinde avantajı hale getirmiştir ${ }^{1}$. Ancak boyutsal stabilitedeki değişim aljinatın en büyük dezavantajıdır. Bu değişim, model dökümünden önce geçen süre, bu süre zarfında bekletilen ortam, aljinatın formülasyonu gibi çeşitli faktörlerden etkilenmektedir $^{2,3}$. Araştırmacılar, boyutsal stabiliteyi korumak için aljinatın derhal ${ }^{4}$ veya en fazla 12 dakika içinde dökülmesini önermektedir ${ }^{5-7}$.

Birçok çalışma, saklama koşullarından bağımsız olarak en iyi sonuçların derhal dökülmesiyle elde edildiğini gösterse de, ölçülerin anında dökülmesi her zaman mümkün olmamaktadır ${ }^{8}$ Bu tür durumlarda, aljinatın nem dengesinin korunması adına ölçülerin nemli kağıt havluya sarılarak bekletilmesi tavsiye edilmektedir ${ }^{9}$. Bekleme süresinin uzatılması için üretici firmalar da döküm süreleri uzatılmış hidrokolloidler üretmişler fakat yine de nemli bir kâğıt havluya sarılmış veya nemli bir kâğıt havlu ile plastik bir torba içinde kapatılmış olarak bekletilmesini gerektiğini belirtmişlerdir ${ }^{10,11}$.

Nem dengesinin korunması özellikle gıda endüstrisi için de önemli bir konudur. Besin kalitesinin kötüye gitmesine neden olan fiziko-kimyasal değişikliklerin bir kısmı nem transferi nedeniyle oluşmaktadır ${ }^{12}$. Nem transferine karşı bariyer oluşturmak amacıyla çoğunlukla apolar yapısı nedeniyle hidrofobik maddeler kullanılmaktadır ${ }^{13}$. Bu tür bariyerler su kaybının yanında su absorbsiyonunu da engellemektedir ${ }^{14,15}$ Birçok çalışma taze meyve ve sebzelerin kurumasını önlemek için "wax" ile kaplandığından bahsetmektedir ${ }^{16,17}$.

Çalışmamızda hidrofilik yapıda olan aljinatın su emilimi ve su kaybını engellemek için hidrofobik yapıda bir materyal olan yağ içerisinde bekleterek meydana gelecek hacim değişikliği miktarının incelenmesi amaçlanmıştır. Literatürde aljinat ölçü materyalinin yağda bekletilerek boyutsal stabilitesini değerlendiren herhangi bir çalışma bulunmamaktadır. "Aljinat ölçü materyalinin boyutsal sta- bilitesi farklı saklama koşullarından etkilenmez" ve "Farklı saklama koşullarında aynı süre bekletilen aljinat ölçü materyallerinin boyutsal değişimi aynıdır" sıfır hipotezleri test edilmiştir.

\section{GEREÇ VE YÖNTEM}

Çalışmada hazırlanacak aljinat ölçülerin standart olarak elde edilmesi için modele uygun olarak hazırlanmış akrilik kaşık kullanılmıştır. Bunu için fabrikasyon olarak üretilmiş bir dişsiz üst çene modeli (KaVo Basic Study Model, KaVo Dental GmbH, Biberarh, Germany) üzerine aljinat ölçü maddesine her yerde eşit kalınlık sağlamak amacı ile 2 tabaka mum (Cavex set up wax, Haarlem, Holland) konmuştur. Akrilik kaşığın sınırları her 3 eksende de hep aynı noktada durması için model üzerindeki sulkus bölgesinin dışındaki alanlarda bitirilmiştir. Akriliğin polimerizasyonu (Paladent 20, Kulzer, Hanau, Germany) sonrasında model üzerinden mumlar temizlenmiş ve kaşığın üzerine aljinatın tutunması için delikler açılmıştır (Resim 1).

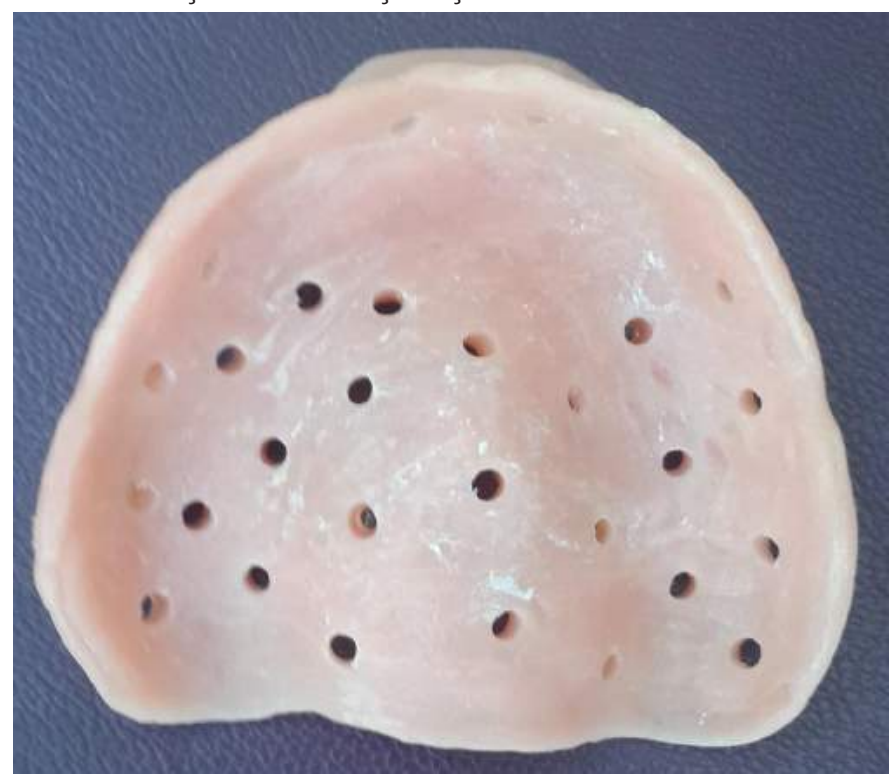

Resim 1. Akrilik kaşık

Çalışmamızda, kullanılan aljinatın (Kromopan, Lascod, Floransa, Italy) su/toz oranı üretici firmanın talimatlarına uygun olarak belirlenmiştir. Oda sıcaklığında (23oC) iyonsuzlaştııımış su kullanılarak 10 saniye otomatik aljinat karıştırıcı (A.H.C.T. Model MIX 1; Gülsa Tıbbi Cihazlar ve Malzeme San. ve Tic. Ltd, İzmir, Turkey) ile karıştırılan aljinat, kaşık içerisine yerleştirip model üzerinde önceden belirlenmiş yerlere temas edinceye kadar kuvvet uygulanmıştır. Daha sonra klinik şartları taklit etmek amacıyla $2 \mathrm{~kg}$ ağırlık ile $3 \mathrm{dk}$ beklenmiştir ve ölçü alma işleminden sonra ölçüler 15 saniye akan su altında yıkanmıştır'18.

Elde edilen ölçüler; oda sıcaklığında tezgâh üzerine (1.grup), oda sıcaklığında saf su içerisinde (2.grup), oda sıcaklığında yağ içerisinde (3.grup) (Resim 2) 


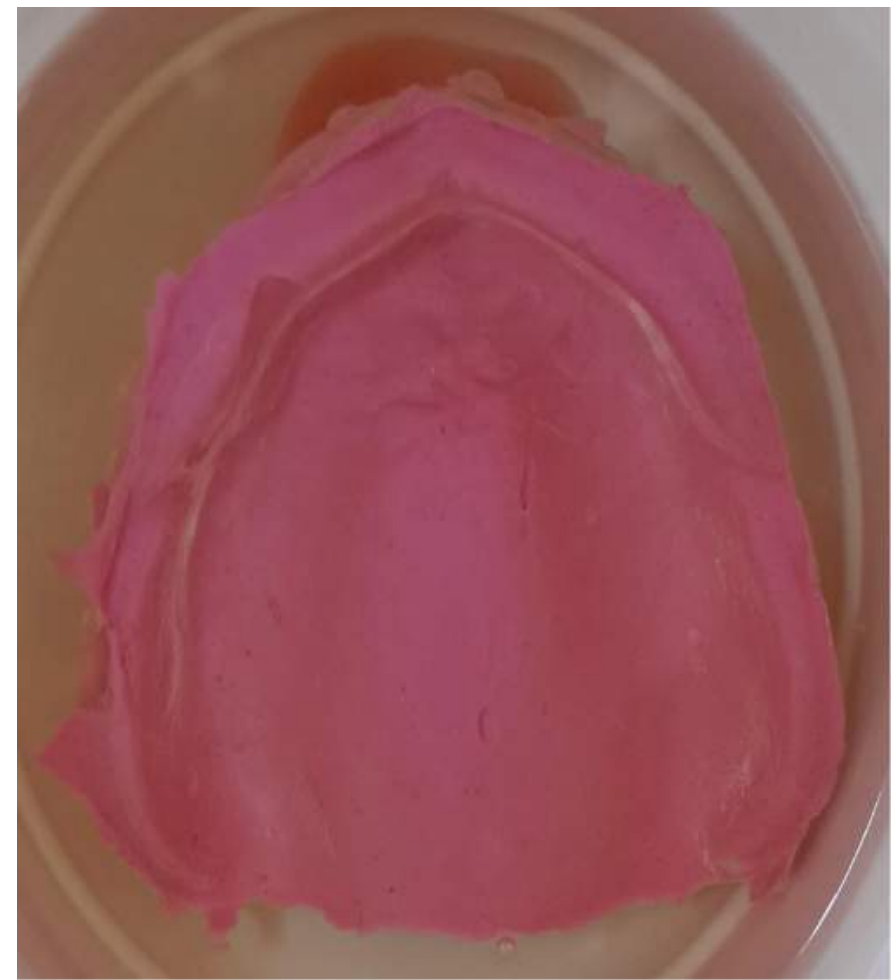

Resim 2. Yağ içerisinde bekletilen grup

oda sıcaklığında nemli bir kağıt havlu ile vakumlu bir poşet içerisinde (4.grup) (Resim 3) bekletilmiştir.

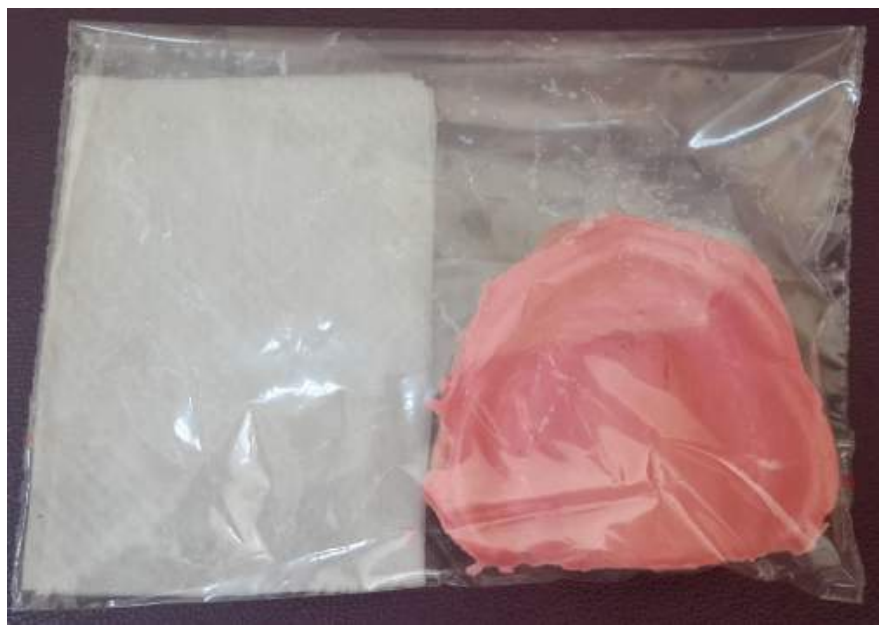

Resim 3. Nemli bir kağıt havlu ile vakumlu bir poşet içerisinde bekletilen grup Her bir grup için $10 \mathrm{kez}$ olmak üzere toplamda 40 adet ölçü alınmıştır ( $n=10)$. Alınan ölçüler 0., 1., 3., 6., 12., 24. 48. ve 72. saatlerde ağız dışı tarayıcı ile taranmış ve negatif ölçü taramaları, pozitif 3 boyutlu sanal modeller haline getirilmiştir. Kontrol grubunu oluşturmak için fabrikasyon olarak üretilmiş ana dişsiz model de aynı tarayıcı ile taranmış ve sanal modeli oluşturulmuştur.

Deney (4 grup ve 8 zaman dilimi için toplam 320 sanal model) ve kontrol grubu için oluşturulan sanal modeller "best fit algorithm" yöntemi ile çakıştırılmış ve ana modelden yüzey olarak sapma miktarları ölçülmüştür. "Best-fit-algorithm" yöntemi referans model ile ölçüm verisi arasındaki ortalama sapma değerinin çok küçük olduğu durumlarda, birleştirme işlemi için tercih edilmektedir. Sapmanın çok olduğu veya referans model üzerinde temsil edilmeyen noktalar, birleştirme işlemi sırasında görmezden ge- linmektedir. Çakıştırma işlemleri 3'er kez tekrarlanmış ve ortalamaları alınmıştır. Elde edilen veriler IBM SPSS 22 (SPSS Inc., Chicago, IL, USA) programında değerlendirilmiştir. Grupların normal dağılıp dağılmadığı Shapiro-Wilk testi sonucunda belirlenmiştir. Gruplar arası farkın anlamlı olup olmadığı ise Ancova testi ile değerlendirilmiştir.

\section{BULGULAR}

Kuru ortamda bekletilen ölçüler için tüm zamanlardaki değerler başlangıca göre istatistiksel olarak farklıdır $(p<0,05)$. Su içerisinde bekletilen örnekler için tüm zamanlardaki değerler başlangıca göre istatistiksel olarak farklıdır $(p<0,05)$. Kuru ortamda bekletilen modellerin 72 . saat sonunda sapma miktarları 27,776 oranında artmıştır (Resim 4).

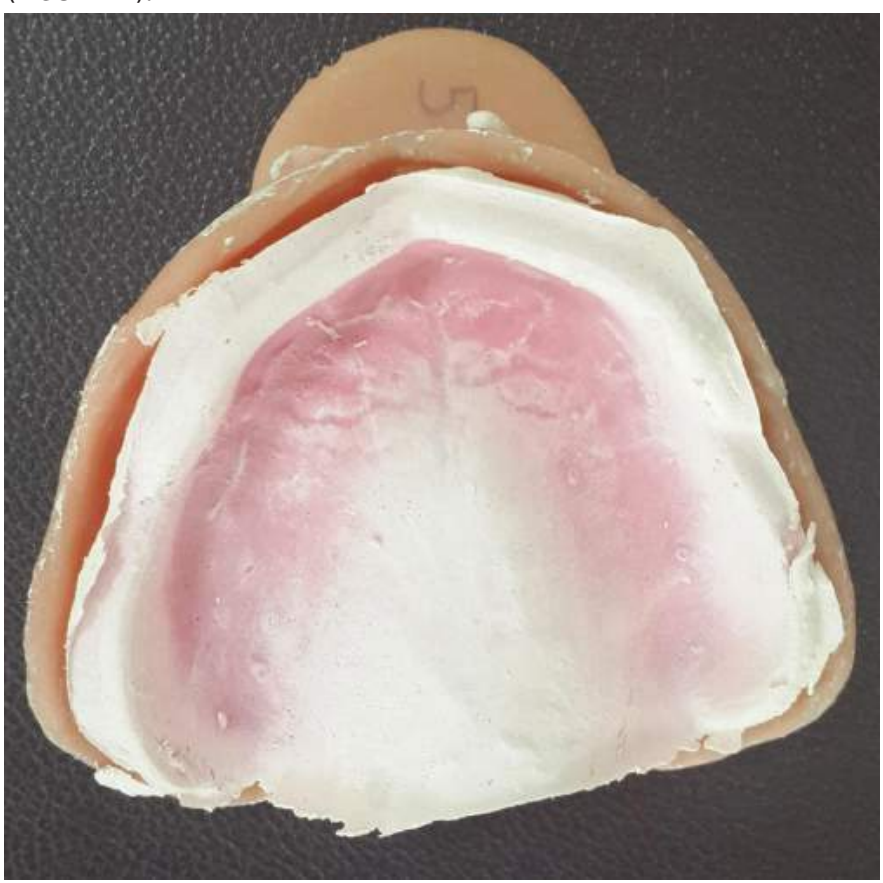

Resim 4. 72 saat sonunda kuru ortamda bekletilen grup

Su içerisinde bekletilen grup için bu oranın 10,553 olduğu görülmüştür (Tablo 1).

Tablo 1. Grupların 72 saat sonundaki artış oranları

\begin{tabular}{|c|c|c|c|}
\hline & 0.Saat & 72.Saat & Artış \\
\hline KURU & 35,080 & 974,404 & 27,776 \\
\hline SU & 23,732 & 250,458 & 10,553 \\
\hline NEM & 45,506 & 95,398 & 2,096 \\
\hline YA $\breve{G}$ & 24,422 & 71,670 & 2,934 \\
\hline
\end{tabular}

Yağ içerisinde bekletilen ölçüler ile su içerisinde bekletilen ölçülerin bütün zaman aralıklarında ana modelden sapma miktarları istatistiksel olarak anlamlıdır ( $p>0,05)$. Yağ içerisinde bekletilen ölçüler ile nemli ortamda bekletilen ölçülerin bütün zaman aralıklarında ana modelden sapma miktarları istatistiksel olarak anlamlıdır $(p>0,05)$. Buna karşın su içerisinde bekletilen ölçüler ile nemli ortamda bekletilen ölçüler arasında bütün zaman aralıklarında ana modelden sapma miktarları açısından istatistiksel olarak 
anlamlı bir ilişki yoktur ( $p>0,05)$.

Yağ içerisinde bekletilen modellerin 72 . saat sonunda sapma miktarları 2,934 oranında artarken nemli ortamdan bekletilen grup için bu oranın 2,096 olduğu görülmüştür. Buna göre bütün saat aralıklarında nem ve yağ içerisinde bekletilen aljinatlar arasında anlamlı bir fark bulunmazken, su ve kuru ortamda bekletilen aljinatların diğer gruplara göre anlamlı derecede boyutsal değişim gösterdiği görülmüştür.

\section{TARTIŞMA}

Aljinat ölçü materyali, nem varlığında sert ve yumuşak doku ayrıntılarını yakalayabilen hidrofilik malzemelerdir. Bu su bazlı malzemeler ucuzdur ve üreticinin talimatlarına uyarak kolayca uygulanabilir. Performansı ile ilgili endişeler arasında, düşük yırtılma mukavemeti, dökülmenin gecikmesiyle boyutsal olarak istikrarsızlık ve yeniden dökülürken doğru dökümlerin üretilememesi sayılabilir ${ }^{19}$. Elde edilen alçı modellerin netliği kullanılan aljinatın boyutsal stabilitesine bağlıdır ${ }^{20-22}$. Bu ölçü materyalinin boyutsal değişimini önemli miktarda etkileyen faktörler saklama süresi ve koşullarıdır ${ }^{23,}{ }^{24}$. Bu nedenle bu çalışmada bu faktörlerin aljinatın boyutsal stabilitesi üzerindeki etkisini araştırmak amaçlanmıştır.

Çalışmamızda yağ içerisinde ve su içerisinde bekletilen modellerin bütün zaman aralıklarında ana modelden sapma miktarları arasındaki ilişki istatistiksel olarak anlamlı gözükse de 72 saat sonundaki ana modelden sapma miktarlarına dair artış oranları sırasıyla 2,934 ve 10,553'tür. Benzer şekilde nemli ortamda ve yağ ortamında bekletilen modellerin de bütün zaman aralıklarında ana modelden sapma miktarları arasındaki ilişki anlamlıdır. Fakat artış oranlarına bakıldığında sırasıyla 2,096 ve 2,934'tür. Anlamlılık düzeyi ( $p$ ) bakımından değerlendirildiğinde su ve yağ gruplarının ilişkisi 0,05 ile 0,1 arasındadır. Çeşitli zaman aralıklarında bu değerler 0,05 değerinden küçük olmadığı için istatistiksel olarak tam bir farklılıktan bahsedilememektedir. Yağ ve nem grupları arasındaki anlamlıık ilişki değerleri ise 0,1 değerinin çok üzerindedir. 72 saat sonunda grupların sapma miktarlarındaki artış oranlarını da göz önünde bulundurulduğunda yağ ile nem grupları arasındaki benzerliğin daha fazla olduğu gözlenmektedir (Tablo 2).

Farzin ve ark. ${ }^{6}$ tarafından yapılan çalışmada standardize bir şekilde elde edilen aljinat ölçülerin \%100 nem altında, 2 farklı sıcaklık derecesinde ve 4 farklı zaman aralığında ölçümleri yapılmıştır. Soğuk ortamda ölçüler bekletilerek döküm zamanının uzatılması amaçlanmıştır. Ölçülerin oda sıcaklığında \%100 nemde hemen veya 12 dakikaya kadar dökülmesi önerilmiştir. Aljinat ölçüler, \%100 nemde $4^{\circ} \mathrm{C}$ 'de saklanırsa 45 dakikaya kadar dökülebileceği belirtilmiştir ${ }^{6}$. Mevcut çaış̧mamızda da benzer şekilde nem dengesinin korunduğu grupta boyutsal değişimin en az olduğu görülmüştür.
Tablo 2. Grupların saatlere göre sapma miktarlarının anlamlılık değerleri

\begin{tabular}{|c|c|c|c|c|c|c|c|c|c|}
\hline Grupl & ler & 1 & 3 & 6 & 12 & 24 & 36 & 48 & 72 \\
\hline \multirow{3}{*}{ Kuru } & Su &, 014 &, 000 & ,000 & ,000 & ,000 & , 000 & ,000 & ,000 \\
\hline & $\mathrm{Nem}$ &, 000 &, 000 &, 000 & 000 & ,000 &, 000 & 000 &, 000 \\
\hline & Yă̆ &, 000 &, 000 & ,000 & ,000 & , 000 & ,000 & ,000 &, 000 \\
\hline \multirow{3}{*}{ Su } & Kuru &, 014 & 000 & ,000 & ,000 &, 000 & ,000 &, 000 &, 000 \\
\hline & Nem &, 067 &, 012 & ,009 &, 035 & ,005 & ,014 & ,018 & ,008 \\
\hline & Yağ &, 064 &, 088 &, 072 &, 059 &, 094 &, 057 &, 083 &, 052 \\
\hline \multirow{3}{*}{ Nem } & Kuru &, 000 &, 000 &, 000 & ,000 & ,000 & , 000 & 000 &, 000 \\
\hline & $\mathrm{Su}$ &, 067 &, 012 & ,009 & 035 & ,005 &, 014 & 018 &, 008 \\
\hline & Yaḡ &, 625 &, 727 & 1,000 & 1,000 & 1,000 & 1,000 & 1,000 & 1,000 \\
\hline \multirow{3}{*}{ Yağ } & Kuru &, 000 &, 000 &, 000 & ,000 &, 000 &, 000 & 000 &, 000 \\
\hline & $\mathrm{Su}$ &, 064 &, 088 & ,072 & ,059 & ,094 &, 057 & 083 &, 052 \\
\hline & $\mathrm{Nem}$ &, 625 &, 727 & 1,000 & 1,000 & 1,000 & 1,000 & 1,000 & 1,000 \\
\hline
\end{tabular}

Cohen ve ark. ${ }^{22}$ tarafından üç farklı aljinatın boyutsal stabilitesi beş farklı saklama koşulunda incelenmiştir. Ölçüler, döküm öncesinde 10 dakika, 30 dakika, 1 saat ve 24 saatlik zamanlarda bekletilmiştir. Ölçülerin hemen dökülmesinin modellerin doğruluğunu arttıracağı belirtilmiştir. ${ }^{22}$ Çalışmamızda da bütün gruplara ait sapma değerleri çeşitli zaman aralıkları ile karşılaştııılığında zaman ile sapma miktarları arasında doğru bir orantının olduğu görülmüştür.

Douglas ve ark. \%100 nemli ortamda 72 saat boyunca depolanan ölçülerin kabul edilebilir bir boyutsal değişime uğradıklarını saptamışlardır ${ }^{24}$. Chen ve ark. \%100 nemli ortamda beklettikleri ölçülerde 24 saatlik bir depolama sonrasında artan bir büzülme kaydetmişlerdir ${ }^{25}$. Dahl ve ark. aljinat materyalinin doğruluğundan ödün vermeksizin \%100 nemli ortamda ölçülerin 24 saat depolanabileceğini belirtmişlerdir ${ }^{26}$. Çalışmamızda da nem dengesinin korunduğu grupta boyutsal değişimin bütün zaman aralıklarında en az olduğu görülmüştür. Yağ içerisinde bekletilen ölçülerdeki boyutsal değişimin bütün zaman aralıklarında nem dengesinin korunduğu gruba yakın olduğu gözlemlenmiştir.

Çoğu diş kliniklerinde ölçülerin saklanması için bir humidorun bulunmadığı belirtilmiştir. Bununla birlikte, humidor koşulları, ölçü ile temas etmeyen ıslak bir havlu içeren hava geçirmez plastik kutular kullanılarak gündelik uygulamada kolayca elde edilebileceği vurgulanmışıı ${ }^{3}$.

Walker ve ark. vakumlu poşette depoladıkları 3 farklı aljinatın zamana göre değişimini araştırmışlardır. Yaptıkları bu çalışmada kullandıkları konvansiyonel aljinatın boyutsal olarak stabil olduğu süreyi 30 dk olarak ölçmüşlerdir¹. Çalışmamızda ıslak kağıt havlu içeren vakumlu poşette (nemli ortamda) bekletilen modellerin 72 saat sonunda 2 kat boyutsal değişime uğradığı saptanmıştır.

Anusavice ve ark. kuru ortamda depolamanın, suyun buharlaşmasından dolayı irreversibl hidrokolloid ölçülerin büzülmesine neden olduğunu, buna karşın, suya temas sonucu, emilimden dolayı ölçülerde şişme ve bozulma meydana geldiğini, son olarak, \%100 nemli ortamda depolamada küçük boyutlu değişiklikler olduğunu, bununla beraber sinerezisden kaynaklanan belirgin büzülmenin 
gözlemlenebileceğini bildirmişlerdir ${ }^{23}$. Çalışmamızda 1. saat sonunda suda bekletilen örneklerde şişme, kuru ortamda bekletilen örneklerde ise büzülme meydana geldiği saptanmıştır. Su içerisinde bekletilen ölçülerde 1 saat sonunda yaklaşık sapma miktarının 2 kat arttığı gözlenirken kuru ortamda bekletilen modeller için bu oran 3 'tür. Yağda bekletilen modellerde ise 72 saat sonunda bu oran yaklaşık 2,5'tir.

Bu çalışmanın pek çok kısıtııı̆ının olduğu görülmektedir. Çalışmamızda ölçüleri yağ içerisinde bekletmek için daldırma yöntemi kullanılmıştır ve model elde edilmeden ölçü taraması yapılmıştır. Model elde edilmesi için alçı dökülmeden önce bu yağın arıtılması ve bu arıtma için ne tür bir kimyasal kullanılacağı, bu kimyasalın aljinatın yüzey özelliklerine, boyutsal değişimine ve alçı ile temas eden yüzeyine etkisi bu çalışmada incelenmemiştir. Ayrıca temizlenemeyen artık yağın yine alçı ile temas eden yüzeyde sorun oluşturup oluşturmayacağı bilinmemektedir. Bu amaçla daldırma yöntemine alternatif olarak püskürtme yöntemi düşünülebilir. Ayrıca aynı yağ kabına birden fazla ölçü koymanın çapraz enfeksiyona neden olma intimali de düşünülmelidir.

\section{SONUÇLAR}

1.Aljinatın boyutsal değişimi hem zamana hem de saklandığı koşula bağlıdır.

2.Aljinatın döküm öncesinde nem dengesinin korunarak saklanması hala en iyi yöntem olarak görülmektedir.

3.Aljinatın yağ içerisinde bekletilmesi döküm öncesi süresinin arttırılmasında yeni bir yöntem olarak göz önünde bulundurabilir.

4. Aljinatın saklama koşullarının iyileştirilmesi, bu durumun klinik uygulanabilirliğinin arttırılması ve oluşturulacak modellerde en az hatanın meydana gelmesi için bu konuda daha çok bilimsel araştırma yapılması gerekmektedir.

\section{KAYNAKLAR}

1. Hiraguchi $H$, Kaketani $M$, Hirose $H$, Yoneyama $T$. The influence of storing alginate impressions sprayed with disinfectant on dimensional accuracy and deformation of maxillary edentulous stone models. Dent Mater J 2010; 29: 309-315.

2. Rohanian A, Ommati Shabestari G, Zeighami S, Samadi MJ, Shamshiri AR. Effect of storage time of extended-pour and conventional alginate impressions on dimensional accuracy of casts. J Dent (Tehran) 2014; 11: 655-664.

3. Erbe C, Ruf S, Wostmann B, Balkenhol M. Dimensional stability of contemporary irreversible hydrocolloids: humidor versus wet tissue storage. J Prosthet Dent 2012; 108: 114-122.

4. Zarb GA, Jacob R, Eckert S, Jacob R. Prosthodontic treatment for edentulous patients. 13th ed., St.Louis, Mosby; 2012.

5. Phoenix RD, Cagna DR, DeFreest CF. Stewart's clinical removable partial prosthodontics. 4th ed., Chicago, Quintessece; 2008.

6. Farzin $\mathrm{M}$, Panahandeh $\mathrm{H}$. Effect of pouring time and storage temperature on dimensional stability of casts made from irreversible hydrocolloid. J Dent (Tehran) 2010; 7: 179-184.

7. Kulkarni MM, Thombare RU. Dimensional changes of alginate dental impression materials - an invitro study. J Clin Diagn Res 2015; 9(8): 98-102.

8. Coleman RM, Hembree JH, Weber FN. Dimensional stability of irreversible hydrocolloid impression material. Am J Orthod 1979; 75: 438-446.

9. Sakaguchi RL, Ferrace J, Powers JM. Craig's restorative dental materials. 14th ed., St.Louis, Mosby; 2018

10. Imbery TA, Nehring J, Janus C, Moon PC. Accuracy and dimensional stability of extended-pour and conventional alginate impression materials. J Am Dent Assoc 2010; 141(1): 32-39.

11. Walker MP, Burckhard J, Mitts DA, Williams KB. Dimensional change over time of extended-storage alginate impression materials. Angle Orthod 2010; 80(6): 1110-1115.

12. Morillon V, Debeaufort $F$, Blond G, Capelle M, Voilley A. Factors affecting the moisture permeability of lipid-based edible films: a review. Crit Rev Food Sci Nutr 2002; 42: 67-89.

13. Callegarin F, Gallo JAQ, Debeaufort F, Voilley A. Lipids and biopackaging. J Am Oil Chem Soc 1997; 74: 11831192.

14. Landmann W, Lovegren NV, Feuge RO. Permeability of some fat products to moisture. J Am Oil Chem Soc 1960; 37: 1-4.

15. Biquet B, Labuza TP. Evaluation of the moisture permeability characteristics of chocolate films as an edible moisture barrier. J Food Sci 1988; 53: 989-998.

16. Hagenmaier RD, Baker RA. Wax microemulsions and emulsions as citrus coatings. J Agr Food Chem 1994; 42: 899-902.

17. Hagenmaier RD, Baker RA. Reduction in gas exchange of citrus fruit by wax coatings. J Agr Food Chem 1993; 41: 283-287.

18. Guiraldo RD, Borsato TT, Berger SB, Lopes MB, Gonini-Jr A, Sinhoreti MA. Surface detail reproduction and dimensional accuracy of stone models: influence of disinfectant solutions and alginate impression materials. Braz Dent J 2012; 23: 417-421.

19. Rubel BS. Impression materials: a comparative review of impression materials most commonly used in restorative dentistry. Dent Clin North Am 2007; 51(3): 629-642.

20. McCabe JF, Walls AW. Applied dental materials. 9th ed., Oxford, Blackwell Publishing; 2008.

21. McNamara JA, Howe RP. Clinical management of the acrylic splint Herbst appliance. Am J Orthod Dentofacial Orthop 1988; 94(2): 142-149. 
22. Cohen BI, Pagnillo $M$, Deutsch AS, Musikant BL. Dimensional accuracy of three different alginate impression materials. J Prosthodont 1995; 4(3): 195-199.

23. Anusavice KJ, Shen $C$, Rawls HR. Phillips' science of dental materials. 12th ed., St.Louis, Elsevier Health Sciences; 2013.

24. Douglass JB, White J, Mitchell R. Clinical acceptability of orthodontic retainers fabricated from stored alginate impressions. Am J Orthod Dentofacial Orthop 1990; 97: 93-97.

25. Chen SY, Liang WM, Chen FN. Factors affecting the accuracy of elastometric impression materials. J Dent 2004; 32: 603-609.

26. Dahl BL, Dymbe B, Valderhaug J. Bonding properties and dimensional stability of hydrocolloid impression systems in fixed prosthodontics. J Prosthet Dent 1985; 53: 796-800. 